\title{
A REFORMA TRABALHISTA COMO SINTOMA DE FRAGILIZAÇÃO DA DEMOCRACIA BRASILEIRA
}

\author{
LABOR REFORM AS A SYMPTOM OF FRAGILIZATION OF BRAZILIAN \\ DEMOCRACY
}

\section{Loiane Prado Verbicaro}

Doutora em Filosofia do Direito pela Universidade de Salamanca (2014), título reconhecido no Brasil pela Resolução no 4814/2016 - UFPA. Mestra em Direitos Fundamentais e Relações Sociais pela Universidade Federal do Pará (2006), com período de estudo na Universidade de São Paulo (USP). Mestra em Ciência Política pela Universidade Federal do Pará (2011). Graduada em Direito pela Universidade Federal do Pará - suma cum laude (2004). Coordenadora do Curso de Graduação em Direito do Centro Universitário do Pará.

\section{Saulo Marinho Mota}

Mestrando em Políticas Públicas e Desenvolvimento pelo Centro Universitário do Estado do Pará, Especialista em Economia do Trabalho pelo CESIT - INICAMP, Especialista em Direito e Processo do Trabalho pelo Centro Universitário do Estado do Pará, Juiz do Trabalho - Tribunal Regional do Trabalho da Oitava Região.

\section{Resumo}

A aprovação da reforma trabalhista em tempo recorde no Congresso Nacional desperta o interesse acadêmico em torno das condições que viabilizaram 0 seu ingresso na agenda governamental e sua aprovação de maneira tão célere. A pesquisa realizada, a partir de um olhar sobre a reforma trabalhista como um conjunto de normas que alterou um ramo do Direito vocacionado à garantia de direitos fundamentais, teve por finalidade analisar se a maneira pela qual ocorreu o seu procedimento de aprovação denuncia um sintoma de fragilização da democracia brasileira. A partir de uma definição procedimental de democracia, acrescida de elementos da democracia orientada pelo processo, e da análise do capitalismo em interação com as noções de liberdade negativa e positiva, concluiu-se que a forma pela qual se deu a aprovação da reforma trabalhista denuncia uma fragilização democrática, na medida em que, apesar da complexidade e desacordos sobre a matéria, a reforma foi operada com velocidade espantosa e 
incomum, aproveitando-se de uma curta janela de oportunidade advinda das mudanças políticas ocasionadas pelo impeachment em 2016. A pesquisa foi qualitativa, de natureza exploratória, mediante utilização das técnicas bibliográfica e documental.

Palavras-chave: Capitalismo. Democracia procedimental. Liberdade negativa e positiva. Reforma trabalhista.

\begin{abstract}
The approval of the labor reform in record time in the National Congress awakens the academic interest around the conditions that made possible its entrance in the governmental agenda and its approval of so fast way. The purpose of this study was to examine the question of labor reform as a set of rules that changed a branch of the law aimed at guaranteeing fundamental rights, to analyze whether the manner in which its approval procedure occurred denounced a symptom of weakening of Brazilian democracy. From a procedural definition of democracy, elements that mark democracy also as a process and the analysis of capitalism in interaction with the notions of negative and positive freedom, it was concluded that the way in which the approval of the labor reform was given denounces a democratic fragilization, inasmuch as, despite the complexity and disagreements on the matter, the reform was operated with astonishing and unusual speed, taking advantage of a short window of opportunity arising from the rupture of democratic constancy through impeachment. The research was qualitative, of an exploratory nature, through the use of bibliographical and documentary techniques.
\end{abstract}

Key-words: Capitalism. Procedural democracy. Negative and positive freedom. Labor Reform.

\title{
1. CONSIDERAÇÕES INICIAIS
}

A Lei 13.467/2017, publicada em 14.7.2017 no Diário Oficial da União, trouxe para o mundo jurídico o texto da denominada reforma trabalhista. A par da sua amplitude e complexidade, chamam atenção duas características presentes tanto no texto da nova legislação quanto no procedimento que culminou na sua aprovação: a profundidade das mudanças substantivas e a velocidade na tramitação e aprovação do então projeto de reforma. ${ }^{1}$

Decerto, a aprovação de uma reforma legislativa dessa magnitude, extensão e profundidade, em lapso temporal tão reduzido, desperta interesse acadêmico dos

1 O acordo para votar o texto da reforma sem qualquer alteração no Senado da República, de modo a conferir a mencionada celeridade ao procedimento, foi expressamente consignado pelo líder do governo na Casa, Senador Romero Jucá, PMDB/RR, conforme se pode atestar nas notas taquigráficas do Senado Federal. (SENADO FEDERAL, 2017). 
mais variados matizes. Dentre a gama de interesses perscrutáveis está a análise do modelo de democracia no bojo do qual foi possível o procedimento com estas características.

A presente pesquisa tem por finalidade, a partir de um olhar sobre a reforma trabalhista como um conjunto de normas que alterou um ramo do Direito vocacionado à garantia de direitos fundamentais, analisar se a maneira pela qual ocorreu o seu procedimento de aprovação denuncia um sintoma de fragilização da democracia brasileira.

Para atingir a finalidade proposta, o trabalho abordará a compreensão das normas trabalhistas como mecanismos de garantia de direitos fundamentais. Em seguida, analisará a dimensão democrática em disputa nesse cenário. A definição de democracia que será trabalhada na pesquisa é a procedimental, matizada por alguns elementos integrantes de uma definição de democracia orientada pelo processo, pois é no bojo da integração destas definições que se torna possível compreender e analisar as razões pelas quais foi possível aprovar uma reforma legislativa profunda com uma velocidade espantosa por meio das tradicionais estruturas democráticas brasileiras.

Além da questão acima, a opção pelo modelo procedimental de democracia também se justifica por se entender que o reconhecimento de eventuais falhas nos processos democráticos - notadamente o desenrolar de propostas legislativas naquela que é tida como a Casa do Povo - pode ofertar ao pesquisador a possibilidade de, identificando as causas das referidas falhas, propor possíveis alternativas que, aprimorando o referido modelo, podem resultar em um duplo ganho: a) o aperfeiçoamento do modelo que melhor habilite o cidadão ao exercício da liberdade positiva, fortalecendo o ideal de autogoverno; b) a resolução de problemas inerentes à democracia pelos próprios protagonistas do modelo - o povo - de maneira global, concertada, dialogada e sistematizada em detrimento de resoluções a partir de sintomas, por instâncias que, apesar de conceitualmente democráticas, não estão ligadas diretamente aos referidos protagonistas do governo democrático.

Nesse sentido, serão analisados os conceitos de liberdade que envolvem tais perspectivas para, em seguida, traçar considerações acerca do papel, influência e maneira de interação do capitalismo e das ideias neoliberais com o modelo procedimental de democracia. Por fim, retornar-se-á à análise da maneira pela qual 
a reforma trabalhista foi aprovada, quando então será respondido se a forma pela qual o procedimento se deu revela a mencionada reforma como um sintoma de fragilização da democracia brasileira.

Dadas as pretensões do trabalho, a pesquisa realizada foi qualitativa, de natureza exploratória, mediante utilização das técnicas de pesquisa bibliográfica e documental.

\section{DIREITOS FUNDAMENTAIS E REFORMA TRABALHISTA}

A proposição de um trabalho ligado à reforma trabalhista torna necessário esclarecer a sua importância no contexto de um Estado obrigado a direcionar suas engrenagens democráticas em busca da concretização de direitos fundamentais.

Iniciando a análise pelo conceito de direitos fundamentais, cumpre apontar a definição trazida por George Marmelstein:

Os direitos fundamentais são normas jurídicas, intimamente ligadas à ideia de dignidade da pessoa humana e de limitação do poder, positivadas no plano constitucional de determinado Estado Democrático de Direito, que, por sua importância axiológica, fundamentam e legitimam todo o ordenamento jurídico (2011, p. 20).

A definição acima deixa claro que tais direitos possuem um aspecto formal e outro material. No aspecto formal, tem-se que os direitos fundamentais traduzem-se em normas positivadas pelo Estado, ou seja, são reconhecidos juridicamente no texto da Constituição. De outro lado, no aspecto material, tem-se por fundamentais os direitos que têm em seu núcleo o viés de garantia e proteção de bens jurídicos necessários e imprescindíveis à tutela da dignidade humana.

No Brasil, ao lado dos direitos sociais previstos no artigo 6ำ da Constituição Federal, a nota de fundamentalidade do Direito do Trabalho restou expressamente reconhecida por meio da positivação dos artigos 7 a 11, que, por sua vez, estão enquadrados no capítulo II do Título II da Carta Magna, título expressamente destinado pelo legislador constituinte à tutela dos denominados "Direitos e Garantias Fundamentais". Logo, seja em função da permanente e incessante construção histórica dos direitos fundamentais ou mesmo em face de uma mera constatação jurídico-positiva, tem-se que o Direito do Trabalho é, por excelência, um conjunto normativo composto por regras garantidoras de direitos fundamentais e com tal 
importância deve ser compreendido e tratado.

Postas as considerações acima, qual o significado e a consequência da constatação da fundamentalidade do Direito do Trabalho? Dentre as várias consequências e significados das formulações acima, destaca-se aquilo que José Joaquim Gomes Canotilho (2001, p. 62-63) denominou de "caráter dirigente da Constituição" ou de "dirigismo constitucional". Segundo o autor, os direitos fundamentais orientam todo o agir estatal e, nesse passo, estabelecem os marcos orientadores que legitimam e vinculam a atuação do legislador.

Diante, pois, deste caráter dirigente e vinculante dos direitos fundamentais sociais, tem-se que o legislador brasileiro, ao tratar do Direito do Trabalho, apesar de ter uma certa discricionariedade conformativa na edição das leis, não detém uma liberdade absoluta para positivar normas trabalhistas que caminhem em sentido oposto às finalidades fundamentais erigidas pela Carta Magna. Em outras palavras, dada a fundamentalidade, e, por conseguinte, a vinculatividade dirigente de que se revestem as normas garantidoras de direitos fundamentais, o legislador brasileiro, ao tratar da reforma trabalhista, não possuía plena liberdade conformativa, restando sua atividade política limitada pelos valores de justiça social que devem ser refletidos nas normas infraconstitucionais.

Esse aporte teórico é importante na medida em que permite vislumbrar o Direito do Trabalho - por conseguinte a reforma trabalhista - enquanto mecanismo de garantia de direitos fundamentais e como vetor normativo condicionante, seja do ponto de vista instrumental ou material, da atividade estatal legislativa. Em outras palavras, a discussão acima travada possibilitou compreender de que modo, à luz das prescrições normativas constitucionais, o legislador infraconstitucional deve pautar sua atividade política no momento em que cogita patrocinar uma profunda alteração do Direito do Trabalho.

\section{DEMOCRACIA}

\subsection{DEMOCRACIA EM SENTIDO DESCRITIVO E NORMATIVO}

Democracia é um conceito em disputa. Há variadas formas de qualificar e conceituar democracia e, igualmente, não há um consenso sobre a melhor maneira de se viver democraticamente e, muitas vezes, em defesa da democracia (de uma 
certa compreensão de democracia), vê-se um recesso democrático.

Antes de delimitar o conceito de democracia é necessário indagar se é possível fazê-lo de uma maneira puramente descritiva ou se esta missão envolverá elementos normativos ou prescritivos.

Sobre esta questão, Sartori aduz o seguinte:

Um sistema democrático é baseado em uma deontologia democrática, e o que é democracia não pode ser separado do que a democracia deveria ser. Uma experiência democrática desenvolve-se com base no desnível entre o dever - ser e o ser, juntamente com traços marcados por aspirações ideais que sempre vão além das condições reais. $(2007$, p. 18).²

Nesse sentido, ao se definir democracia, fundem-se no conceito produzido tanto o elemento normativo, que aponta para o que a democracia deve ou deveria ser, quanto o elemento descritivo, que religa a definição ao âmbito do ser, não deixando com que o conceito a ser construído fuja das experiências democráticas vividas ou em vivência.

Da mesma forma, Dworkin afirma que a democracia é um conceito interpretativo, explicitando seu pensamento da seguinte forma:

A democracia, repetimos, é um conceito interpretativo ${ }^{3}$ : as pessoas discordam sobre o que é a democracia. Escolhemos entre concepções concorrentes, identificando algum valor distinto ou conjunto de valores que expliquem melhor, se algum deles o puder fazer, o que tem ela de bom. (2012, p. 390).

Em outras palavras, assim como referido por Sartori, Dworkin admite que a definição de democracia envolve percepções de mundo que não são compartilhadas coletivamente de maneira uniforme, fundindo-se na definição elementos normativos e descritivos. A democracia, então, na visão destes dois autores, não é um conceito criterial, isto é, um tipo de conceito que é partilhado coletivamente pelo recurso psicológico aos mesmos critérios de identificação. (DWORKIN, 2012, p. 166; VERBICARO, 2018).

O presente trabalho não tem por escopo desenvolver uma pesquisa no sentido de atestar se, de fato, a democracia é um conceito criterial ou interpretativo,

2 Un sistema democrático está sustentado en una deontologia democrática, y lo que la democracia es no puede separase de lo que la democracia debería ser. Una experiencia democrática se desarrolla a caballo del desnivel entre el deber ser y el ser, a lo largo de trayetoria marcada por unas aspiraciones ideales que siempre van más allá de las condiciones reales.

3 Nas palavras do próprio Dworkin: "Partilhamos um conceito interpretativo, quando o nosso comportamento coletivo, ao usarmos esse conceito, se explica melhor considerando que o seu uso correto depende da melhor justificação do papel que para nós desempenha." (2012, p. 166) 
como referido pelos autores acima. Não obstante, é importante reforçar a ideia de disputa, interpretação e divergência na delimitação de modelos democráticos.

\subsection{DISTINTAS PERSPECTIVAS DE DEMOCRACIA}

Como visto, há a possibilidade de confeccionar definições distintas de democracia, a depender dos diversos critérios compartilhados coletivamente que influem na sua concepção. Esta diversidade resulta na discussão de várias e distintas abordagens da democracia, as quais foram agrupadas por Charles Tilly em quatro blocos: constitucional, substantiva, orientada pelo processo e procedimental (2013, p. 21).

$\mathrm{Na}$ abordagem constitucional, o foco se dá sobre as leis sancionadas por um regime acerca da atividade política. Esta espécie de abordagem foca-se nos arranjos legais concebidos para viabilizar a atividade política, permitindo, a depender do desenho das estruturas estatais e das instâncias de poder formatadas, identificar democracias organizadas em monarquias constitucionais, sistemas presidenciais e conformações parlamentares (TILLY, 2013, p. 21). A abordagem constitucional não será utilizada no presente trabalho pois responder se a maneira pela qual a reforma trabalhista foi aprovada revela sinais de fragilização da democracia brasileira exige a adoção de uma definição de democracia que vá além das questões relativas à maneira pela qual o Estado se organiza para exercitar seus poderes.

A democracia substancial, por sua vez, nas palavras de Tilly, pode assim ser identificada:

Abordagens substantivas focam nas condições de vida e de política que um determinado regime promove: esse regime promove o bem-estar do ser humano, a liberdade individual, a segurança, a equidade, igualdade social, deliberação pública e resolução pacífica dos conflitos? Em caso afirmativo, podemos estar inclinados a chamá-lo de democracia, a despeito daquilo que está escrito em sua constituição. (2013, p. 21)

A orientação para um modelo substancial permite colocar valores e objetivos sociais à frente da forma, maneira ou procedimento pelo qual aqueles valores $\mathrm{e}$ objetivos vieram a se tornar realidades normativas ou mesmo políticas públicas. $A$ análise e conclusão sobre o caráter democrático de um determinado regime repousa então na sua capacidade de implementar os projetos constitucionais sobre os quais se assentaram as instituições políticas, relegando-se a um segundo plano a forma 
pela qual o alcance do objetivo se dá e também a instância política normativamente responsável por atingir essas metas constitucionais. Seria realmente importante que o atingimento das metas constitucionais seja obtido por este ou aquele poder? Poder Executivo? Legislativo? Judiciário? Para a corrente substancial, é democrático o regime que habitualmente alcança tais objetivos, independentemente da instância política que a concretize.

Linhas atrás, viu-se que o Direito do Trabalho consubstancia-se em um conjunto de normas vocacionadas à garantia de direitos humanos, chamando-se a atenção para a importância de uma mudança profunda neste conjunto de normas, como ocorrido por meio da reforma trabalhista. Como aqui se fez ver, a noção de democracia substancial liga-se justamente à capacidade de o Estado atingir os objetivos constitucionais de, entre outros, preservar, garantir e promover direitos fundamentais, dentre eles, então, os direitos abarcados pela legislação trabalhista. Ora, partindo-se dessas premissas, bastaria demonstrar, por meio de análises materialmente concretas das normas que integram a reforma trabalhista, que as novas regras atingem ou afrontam direitos sociais trabalhistas que têm assento de fundamentalidade na Carta Constitucional para então concluir que a reforma ataca o conceito de democracia substancial, fragilizando-a.

Em que pese a relevância desta espécie de análise, uma tal opção teria o condão de analisar a legitimidade constitucional da reforma trabalhista - em uma visão democrática substancial - mas olvidaria da apreciação as razões pelas quais foi possível aprovar, com incomum velocidade, tais normas por meio dos tradicionais condutos formais democráticos.

Tilly ainda desenvolve a abordagem voltada para o processo, a qual identifica "um conjunto mínimo de processos que precisam estar continuamente presentes para que uma situação possa ser considerada democrática." (2013, p. 23). Tilly destaca as construções feitas por Robert Dahl, que organizou cinco critérios relativos ao processo caracterizador de uma democracia: participação efetiva, igualdade de voto, entendimento esclarecido, controle da agenda e inclusão dos adultos. (2013, p. 23)

Esses critérios evidenciam como uma determinada associação - por exemplo, uma comunidade politicamente organizada - deve funcionar para que seja considerada democrática, descrevendo um conjunto interligado de processos políticos (TILLY, 2013, p. 24). Como se verá mais adiante, a democracia em sentido 
procedimental pode ser compreendia de maneira interligada com a compreensão voltada ao processo, notadamente em relação aos critérios construídos por Dahl.

A leitura do texto de Tilly revela que as abordagens voltadas para o processo ofertam um bom potencial de análise para estudos que se proponham a mapear e identificar elementos que devem estar presentes em uma sociedade para que ela seja considerada democrática, concepção que pode ser retomada de forma interligada à noção de democracia procedimental.

Como já anunciado, a pretensão do trabalho é responder se a aprovação da reforma trabalhista, mormente da forma em que tal se deu e também considerando o teor da mudança, revela um sintoma de debilidade do modelo democrático. A abordagem voltada ao processo, construída de maneira interligada à noção de democracia procedimental em razão de os elementos centrais desta se tocarem com os eixos centrais daquela, apresentam parâmetros adequados para responder à indagação de pesquisa formulada.

\subsection{A DEFINIÇÃO PROCEDIMENTAL DE DEMOCRACIA}

A definição procedimental de democracia, por sua vez, centra seu foco sobre um conjunto de práticas governamentais. Nesse sentido, será considerado democrático um determinado regime se ele atender essas práticas. Segundo Tilly, neste tipo de definição, a maior parte dos observadores preocupa-se com questões atinentes ao processo eleitoral, por exemplo. Procuram verificar se as eleições são competitivas, inclusivas, capazes de promover mudanças nos ocupantes dos cargos públicos e se promovem novas políticas públicas. (TILLY, 2013, p. 22)

Com efeito, a preocupação com as eleições é apenas um dos exemplos dos focos sobre os quais se debruça uma concepção procedimental de democracia, cabendo, pois, prosseguir na busca de descrições adicionais desta espécie de definição e na pesquisa de outros elementos procedimentais que podem compor este modelo.

A explicação de democracia em sua feição procedimental pode ser também compreendida na definição fornecida por Barzotto, nos seguintes termos: "como um método de tomada de decisões políticas, composto de uma série de procedimentos e regras, dentre as quais a principal é a regra da maioria." (2005, p. 131)

Em um primeiro contato, poder-se-ia simplesmente identificar, então, a 
democracia com um procedimento de tomada de decisões pela maioria das pessoas presentes em uma espécie de assembleia, revelando-se uma estreita identificação entre democracia e majoritarismo. Este aspecto da democracia procedimental permite uma religação com um dos critério de Robert Dahl indicados na definição de democracia orientada pelo processo: a igualdade de voto. (TILLY, 2013, p. 23). A democracia, no sentido ora apresentado, identifica-se com um procedimento que, conferindo igual peso ao voto de cada um dos participantes, determina, pelo princípio majoritário, o agir estatal.

Com efeito, embasando um conceito aparentemente singelo de democracia, existem complexos pressupostos que dão sustentação àquele. $O$ primeiro pressuposto a ser explorado pode ser explicado a partir da busca pela resposta à pergunta: por que precisamos de um método democrático e majoritário?

Como visto, a democracia foi conceituada como método para tomada de decisões políticas. Desta forma, a sua necessidade e legitimidade estão ligadas à existência de desacordos entre os integrantes de uma determinada comunidade acerca da providência ou atitude que o corpo coletivo deverá tomar na situação em debate. Ou seja, se inexistissem desacordos não seria necessário um método baseado no procedimento.

Este é um ponto central para a compreensão da democracia em sua feição procedimental. A concepção está assentada sob a premissa de que consensos e uniformidades em uma comunidade política são a exceção e não a regra. Subsidiando esta premissa está uma visão segundo a qual as noções de "bem" e de "justiça" carecem de objetividade, o que novamente coloca a democracia procedimental em franca oposição à democracia substancial.

Jeremy Waldron assevera que, mesmo que se possa cogitar da existência de uma verdade moral ou uma noção correta de "bem" ou "justo", filósofos morais ou políticos não foram capazes de estabelecer qualquer pressuposto epistemológico ou método compartilhado que permitisse enfrentar os desacordos sobre tais pontos (WALDRON, 2005, p. 212, VERBICARO, 2017). O alerta feito pelo autor é de todo sensível na vida cotidiana, pois toda e qualquer tentativa de convencimento acerca do eticamente correto ou do moralmente bom sempre vem condicionada a uma adesão bem própria - e porque não dizer privada - da inventividade daquele que tenta convencer. Não há, até o presente momento, uma espécie de método epistemológico que, uniformizando o canal de pressupostos avaliativos de maneira 
publicamente compartilhada, permita uma resposta objetiva acerca do que é bom e correto e que, por conseguinte, deva guiar a decisão.

A conclusão relativa à impossibilidade de um estatuto objetivo para a resolução de questões morais e políticas leva inevitavelmente à outras considerações, desta feita alusivas à igualdade e à liberdade.

Se, como visto, não há um caminho publicamente compartilhável para a aferição objetiva do que é moralmente bom ou justo, quais das propostas de ação e de decisão devem prevalecer? Que tipo de método e de regra de ouro poderia ser utilizado para resolver estes impasses? O método em questão é a democracia e a regra de ouro é o princípio majoritário. Assim, se duas ou mais pessoas discordam sobre a melhor decisão política a ser tomada, após a necessária abertura para debates e tentativas de convencimento recíprocas, resolve-se o impasse adotando a decisão que contou com a superioridade numérica.

A partir das considerações em apreço, pode-se notar que a democracia procedimental está calcada nos pilares da igualdade formal e da liberdade. Está construída sob o pilar da igualdade formal na medida em que, ao decidir adotar a decisão escolhida pela maioria, confere o mesmo peso participativo aos votantes, tratando-os de maneira igual. O apelo à regra da maioria evidencia, então, que, embutida na definição de democracia, está a noção de igualdade de voto igualdade formal - critério alinhavado por ocasião da definição de democracia orientada pelo processo e que a liga à dimensão igualitária de consideração de cada pessoa dentro do espaço político. A imprescindibilidade do recurso à regra da maioria possui como pressuposto não apenas o valor igualdade, mas também a ideia de liberdade.

O sentido moderno de liberdade é aquele que protege o indivíduo contra o arbítrio do Estado. Trata-se da conhecida liberdade dos modernos (CONSTANT, 1985), focada na liberdade de não interferência do Estado na esfera privada, notadamente na seara dos planos éticos de vida e também conhecida como liberdade negativa.

Na medida em que, nos termos acima, a liberdade é definida e compreendida como um instinto humano, o conceito de liberdade assentando no direito de não intervenção estatal parece caminhar no sentido de acolher e reforçar o princípio majoritário ínsito à democracia procedimental. É que uma concepção de liberdade negativa como um direito de não intervenção estatal, seja no que toca aos projetos 
de vida privada de cada pessoa - o campo ético mencionado por Dworkin ${ }^{4}$ - seja no que se refere às questões relacionadas aos demais setores da vida que se tocam com as vidas e projetos de outros cidadãos - isto é, no campo da moralidade política, como classifica Dworkin - funciona como uma espécie de anteparo ou barreira criada de tal maneira que exige continuamente a presença de um elemento ao mesmo tempo condicionante e legitimador para a intervenção estatal. Em outras palavras, a importância e prevalência da liberdade negativa é tão forte que o Estado somente pode atingir determinadas esferas da vida privada do indivíduo e, quanto à intervenção nas outras esferas, somente pode atuar mediante autorização da maioria e nos estritos termos desta autorização. A regra majoritária da democracia procedimental é, neste aspecto, uma garantia de proteção da liberdade negativa, ou liberdade dos modernos.

A liberdade positiva pode aqui ser apreendida por meio das lições de Cunningham, o qual, com base nas advertências feitas por Waldron acerca da distinção entre liberdade dos modernos e dos antigos construída por Benjamin Constant (1985), assevera que se trata de liberdade ou direito "que envolve participação direta e coletiva em um autogoverno." (CUNNINGHAM 2009, p.70). Em outras palavras, trata-se do direito de participação política na construção das normas e regras que irão justamente definir limites interventivos sobre a liberdade dos membros da comunidade política. Fecha-se, pois, o círculo de pertinência e adequação da democracia procedimental com a liberdade. Sendo inevitável algum grau de limitação da liberdade dos indivíduos por parte do Estado (caráter não absoluto da liberdade negativa), a garantia de participação política a todos os membros da comunidade na criação das normas limitadoras, legitima politicamente a intervenção do Estado na liberdade negativa dos indivíduos, pois os derrotados no procedimento majoritário terminaram por ser autores das decisões que serão aplicadas a eles mesmos, fechando-se a ideia de junção de liberdade e autogoverno.

Note-se, então, que a democracia procedimental, ao fechar o círculo da liberdade com a noção positiva desta, termina por dotar o sistema de mecanismos que, em tese e ao menos formalmente, seriam capazes de espelhar decisões políticas tidas como corretas, boas e justas pela maioria da sociedade, superando os

4 Dworkin bem separa o campo ético do campo da moral e da moral política em Justiça para Ouriços (2014, p. 500; p. 567-568) 
impasses por meio da participação legítima daqueles que irão se submeter às novas regras. Neste ponto, religa-se a noção de democracia orientada pelo processo no que toca à presença da participação efetiva como elemento essencial para a experiência democrática.

Ainda no que toca à noção de liberdade positiva, relembra-se que o critério de Dahl explorado por Tilly relativo ao "Entendimento Esclarecido" é essencial para que se possa conceber o pleno e efetivo exercício da liberdade positiva em determinada comunidade política. Explicitando a teoria construída por Dahl, Tilly assevera o seguinte: "Dentro de limites razoáveis de tempo, cada membro deve ter oportunidades iguais e efetivas de aprender sobre as alternativas de políticas mais relevantes e suas prováveis consequências." (2013, p.23) Em outras palavras, somente há liberdade positiva onde há participação efetiva e entendimento esclarecido. Sonegados estes critérios, tem-se apenas aparência de exercício de liberdade positiva.

Consideradas as premissas acima, tem-se, então, que o efetivo alcance do autogoverno da comunidade política por meio da democracia procedimental depende da garantia, não apenas formal, de uma efetiva liberdade positiva e participativa - que somente se materializam com participação e entendimento esclarecido. A fragilização deste tipo de liberdade resultará, por outro lado, em um sistema que, sob a aparência democrática - dada a permanência de aplicação da regra majoritária calcada na ideia de igualdade de votos - termina sendo instrumentalizado pelos detentores ocultos de poderes de outra ordem em benefício próprio, ruindo todo o ideal de autogoverno ou de autonomia.

\section{CAPITALISMO, DEMOCRACIA E LIBERDADE POSITIVA}

Estabelecida a importância de se efetivar, de fato, medidas que garantam e intensifiquem o exercício da liberdade positiva, cabe, então, analisar, dentre os possíveis fatores que tentam obstaculizar a referida efetivação, aquele que, decerto, vem merecendo uma considerável atenção dos teóricos: o capitalismo e sua expansão em um contexto neoliberal. Segundo Faria:

Democracia e capitalismo sempre guardaram uma forte, permanente e indissolúvel relação de tensão. Por um lado, o capitalismo é uma força de acumulação que não suporta limites. É uma mecânica cuja força motriz é a continuação de uma acumulação sem fim. Por isso, a acumulação 
capitalista tem de ser mantida tão desimpedida quanto possível de restrições legais e de constrangimentos fiscais determinadas por critérios de ordem política e ideológica. Por outro lado, como responde a anseios e interesses definidos com base no sufrágio universal e na regra da maioria, a democracia representativa possibilita a imposição de limites à lógica capitalista e ao jogo financeiro, com o objetivo de assegurar algum equilíbrio entre enriquecimento privado e justiça distributiva. (2017, p. 57)

Vê-se, pois, que, de acordo com o que expôs Faria, o capitalismo e seu objetivo eterno de acumulação infinita de capital exige do Estado uma postura de nenhuma ou pouca intervenção, notadamente na área econômica, respeitando, no mais elevado grau possível, a liberdade negativa, de forma que não venha a implementar obstáculos na continuidade do referido processo de acumulação.

Prosseguindo na identificação dos caracteres do capitalismo e da sua forma de vida, Harvey anuncia que:

O capital não é uma coisa, mas um processo em que o dinheiro é perpetuamente enviado em busca de mais dinheiro. (...) A continuidade do fluxo na circulação do capital é muito importante. O processo não pode ser interrompido sem incorrer em perdas. Há também fortes incentivos para a velocidade da circulação. Aqueles que podem se mover mais rapidamente pelas diversas fases de circulação do capital acumulam lucros superiores aos de seus concorrentes. (2011, p. 41-42).

A consideração central que une as falas dos dois autores acima caminha no sentido de reconhecer que o capitalismo exige um afrouxamento dos controles e regulações estatais sobre as pedras centrais de sua atuação rumo à acumulação infinita de capital. Em outras palavras, o capitalismo atua no sentido de reforçar sua liberdade negativa, colocando-se em um fronte de combate contra aquilo que em tese e formalmente se espera ser o resultado do exercício da liberdade positiva dos demais membros da sociedade: a edição de normas capazes de regular o capitalismo para que este seja impedido de concretizar um estado de coisas capaz de fazer ruir a democracia e as preferências da maioria legitimamente materializadas por seus representantes. Vê-se, pois, que a dinâmica capitalista tende a produzir barreiras e ataques à democracia todas as vezes que os frutos do agir democrático possam vir a representar ameaças contra o livre fluir do capital rumo à acumulação e reprodução do mesmo. A questão que agora se descortina é saber de que forma o capitalismo age para estabelecer estas barreiras e ataques antidemocráticos.

Destaca-se que o capitalismo pode engendrar formas de atuação antidemocrática inconscientes e conscientes. Diz-se que a primeira forma é inconsciente porque os seus efeitos digressivos à democracia decorrem de um efeito 
conexo à dinâmica própria do capitalismo. Nesse campo, não se trata propriamente de um plano ou conjunto de ações gestado por capitalistas com o intuito deliberado de afetar a democracia, mas de efeitos decorrentes da dinâmica e da lógica capitalistas no espírito ou no inconsciente coletivo dos membros de uma comunidade capitalista. Os efeitos em questão podem ser resumidos sob a denominação de "passividade política".

Essas ideias podem ser compreendidas por meio dos seguintes apontamentos de Rosenfield:

\begin{abstract}
O advento de uma economia de mercado imprime, pela eliminação gradativa ou violenta de formas não - mercantis, um novo movimento tendencial à sociedade, que torna o cidadão um mero objeto de troca. (...) A passividade política observada nos Estados modernos é ela mesma decorrente do predomínio crescente dos valores individualistas de uma sociedade regida pela ideia do bem - estar material e do medo de enfrentarse a um Estado poderoso cujos tentáculos tendem a controlar a vida de cada um. (1984, p. 21-23)
\end{abstract}

Nos termos do que acima foi apontado, tem-se, então, que a intensificação do ideário liberal - e notadamente da agenda neoliberal, que potencializa ainda mais as exigências abstencionistas inauguradas pelo liberalismo clássico - produz no seio da sociedade, ainda que inconscientemente, um verdadeiro modo de vida capitalista pelos integrantes da sociedade, que passam a construir individualmente projetos de vida boa atomizados e calcados, igualmente, no pressuposto de um direito radical a uma liberdade negativa, isto é, exigindo-se uma completa abstenção dos demais membros da sociedade e das instâncias políticas institucionalizadas na construção e execução desses projetos de vida. O resultado é a produção de uma sociedade plural, mas atomizada, sem qualquer amálgama de solidariedade social, e, por conseguinte, incapaz de gestar planos e projetos políticos coletivamente construídos. Em síntese: uma sociedade politicamente apática e passiva.

Um tal estado de apatia e passividade política expressa, então, a afetação prejudicial de um pressuposto democrático inarredável para o funcionamento da democracia, isto é, a efetiva participação política de todos os membros da comunidade na elaboração dos projetos políticos que serão submetidos aos mesmos. Rui o ideal de autonomia ou de autogoverno. Como dito, essa é a forma inconsciente de ação antidemocrática do capitalismo.

A ação capitalista antidemocrática consciente refere-se às tentativas diretas de minar as estruturas e engrenagens que se destinam justamente à garantia do 
exercício eficaz da liberdade política por todos os membros da sociedade. Neste ponto, destaca-se, dentre um mar de exemplos, a seguinte tentativa predatória: financiamento empresarial de campanhas políticas sem a devida transparência, de modo a estabelecer um vínculo não republicano com o candidato eleito, fazendo com que este indivíduo esteja mais propenso a atender lobbys de grandes corporações privadas do que se dispor a debater politicamente de maneira transparente e vinculada a uma responsabilidade política com os eleitores, na arena pública. Trata-se, pois, de utilização, pelo capital, das falhas jurídico-institucionais do sistema político de modo a fragilizar o pressuposto democrático inarredável da efetiva e material liberdade positiva: a participação política.

Não é pretensão deste ensaio esmiuçar os exemplos destes ataques, mas explicitar algumas características que, uma vez presentes no procedimento que culmina com a edição de uma lei marcada por um viés puramente favorável ao mercado, indicam que o resultado obtido é fruto da fragilização das instâncias democráticas responsáveis pelo exercício direto da liberdade política positiva. Uma vez explicitadas estas características, será possível responder se a reforma trabalhista evidencia um sintoma da aludida fragilização.

\section{A REFORMA TRABALHISTA COMO SINTOMA DE FRAGILIZAÇÃO DA LIBERDADE POSITIVA E DA DEMOCRACIA}

Duas características serão aqui analisadas para aferição do caráter democrático do procedimento que culminou com a aprovação da reforma trabalhista: a) a velocidade com que a reforma trabalhista ingressou na agenda governamental e foi aprovada; b) a verificação da legitimidade democrática - legitimidade no sentido eleitoral - da agenda vencedora.

De um modo geral, é democrática a lei ou política pública que resulta de processos apoiados na legitimidade do voto - liberdade política positiva - de um lado e, de outro, quanto mais rápida é a aprovação de uma lei, menores são as chances de que se trate de um diploma crivado pelo contraditório democrático. ${ }^{5} \mathrm{~A}$

5 Deixa-se desde logo registrado que em algumas ocasiões a maior rapidez na aprovação de medidas legislativas pode derivar de um verdadeiro consenso ou ausência de conflito sobre a matéria. De toda sorte, não parece ser este o caso da reforma trabalhista, uma vez que da mesma forma em que legislação social do trabalho foi implementada depois de longos processos de luta dentro de um cenário democrático procedimental - o que evidencia o elevado grau de desacordos 
velocidade exacerbada na aprovação de uma lei que naturalmente desperta posições dramaticamente antagônicas revela uma espécie de indício de atropelo e fragilização de uma participação efetiva calcada em um entendimento esclarecido no procedimento de debate e de aprovação da lei, elementos que, como visto, integram a noção de democracia adotada neste trabalho.

\subsection{ANALISANDO QUEM PATROCINOU A REFORMA TRABALHISTA E A VELOCIDADE DO SEU PROCEDIMENTO DE APROVAÇÃO}

Kingdon assevera que os eventos que cercam a política possuem regras e dinâmicas próprias, dependendo o sucesso de inclusão de um tema na agenda do governo da percepção eficiente da atmosfera política nacional. A título de exemplo, o autor apontou as eleições, eis que estas "trazem novos governos e novas configurações partidárias ou ideológicas ao Congresso, e grupos de interesse de vários tipos pressionam (ou não conseguem pressionar) o governo com suas demandas" (2007, p. 229). E prossegue afirmando que "um novo governo, por exemplo, muda as agendas completamente ao enfatizar as suas concepções dos problemas e suas propostas, e torna bem menos provável que assuntos que não estejam entre as suas prioridades recebam atenção".(2007, p. 229).

Cabe então a pergunta: a agenda do governo eleito em 2014 contemplava uma reforma trabalhista nos moldes recém-aprovados? A resposta à pergunta em apreço poderia contemplar uma extensa e minudente demonstração dos movimentos das forças políticas da época. Porém, dado o escopo do estudo, apontam-se dois indicativos que bem podem resumir o posicionamento do governo eleito para o quadriênio 2014-2018 acerca da necessidade de patrocinar uma profunda alteração da legislação trabalhista. Os indicativos podem ser capturados tanto através dos noticiários da época ${ }^{6}$, que bem demonstravam a resistência da então Presidente eleita acerca do tema, quanto por meio do programa de governo apresentado pela chapa à época da eleição 7 . Em ambas as perspectivas, pode-se perceber que a reforma trabalhista, tal como ao final ocorrida, não integrava o

\footnotetext{
sobre a matéria - as mudanças e reformas sobre este conjunto de regras também tem o mesmo potencial plural. Logo, ao menos no que toca à reforma trabalhista, pode-se com razoável segurança afirmar que a maior rapidez na aprovação de um profundo projeto de reforma nesta área é inversamente proporcional ao grau de contraditório democrático que precede a aprovação.

6 Ilustrando o afirmado, aponta-se a reportagem constante do site de notícias G1. (2016)

7 Conferir o Programa de Governo da Presidente eleita (PT, ROUSSEFF, 2014)
} 
programa de governo dos então candidatos à Presidente e Vice-Presidente da República e também não estava incorporada à agenda do governo eleito.

Ora, se, como afirmado por Kingdon, as eleições configuram, por excelência, a manifestação de um fluxo político importante para o estabelecimento da agenda de governo, decorrência direta que é da democracia representativa, e, como visto, a reforma trabalhista, tal como ao final desenhada, não figurava como um dos itens da agenda governamental recém-eleita, o que propiciou o ingresso de tal temática na agenda e, como exposto na introdução deste trabalho, sua célere aprovação? Dentro da dinâmica própria do fluxo político, a resposta pode ser encontrada nas mesmas lições de Kingdon, eis que, por meio do impeachment da Presidente Dilma Rousseff, materializado no dia 31.8.2016, surgiu um novo governo dentro do governo recém-eleito no final do ano de 2014 e, como ressaltado pelo mencionado Professor, com um novo governo, novas agendas foram estabelecidas.

Sobre este ponto, poder-se-ia contraditar que o impeachment não teve o condão de estabelecer um novo governo, pois, com a queda da então Presidente, assumiu seu Vice-Presidente. Porém, além da divergência entre o programa de governo apresentado pela então candidata à Presidência e a carta de propostas materializada pelo PMDB, partido do então Vice-Presidente, no documento "Uma ponte para o futuro", também a construção da equipe de governo do novo Presidente deixou bem evidenciado que, doravante, tratava-se de um novo governo, como abaixo será demonstrado.

Ainda no dia 12.5.2016, com a Presidente da República afastada pelo Senado, o novo Presidente deu posse a 22 novos ministros. Desse total, 6 foram entregues ao PMDB, 2 ao PSDB, 1 ao Democratas - DEM, 2 ao Partido Progressista - PP, 1 ao Partido Trabalhista Brasileiro - PTB, 1 ao Partido Verde - PV, 1 ao Partido Social Democrático - PSD, 1 ao Partido da República - PR e 1 ao Partido Popular Socialista - PPS. Os 6 postos restantes foram distribuídos a atores não filiados à partidos políticos. Posteriormente, o novo Presidente ainda distribuiu um cargo ministerial ao Partido Socialista Brasileiro - PSB e outro ao PMDB.

A primeira constatação digna de nota é a ausência de participação do Partido dos Trabalhadores - PT, legenda da Presidente deposta, no novo governo, em oposição aos 12 cargos ocupados anteriormente no universo de 39 ministérios.

O segundo fato é a presença do PSDB e do DEM, que eram oposição ao governo eleito, como detentor de cargos ministeriais no novo governo. 
Uma terceira nota refere-se à permanência do PMDB, PP, PTB, PSD e PR com cargos tanto no antigo quanto no novo governo. Tais constatações corroboram, portanto, a afirmação do efetivo surgimento de um novo governo, promotor, por conseguinte, de uma nova agenda, distinta daquela aprovada pelo crivo democrático das eleições. O impeachment, pois, da Presidente Dilma Rousseff, representa a culminância dos fluxos políticos que viabilizaram o ingresso da reforma trabalhista na agenda do governo.

$\mathrm{Na}$ medida em que os fundamentos da reforma concentraram-se em reduzir as proteções trabalhistas em benefício de maior liberdade para o capitalista gerir seus negócios - liberdade negativa - e considerando-se que a aprovação daquela somente foi possível após a troca de um governo dentro do mesmo governo, evidencia-se a estreita ligação entre as exigências abstencionistas do capital e a ruptura do fluxo democrático lastreado no sufrágio universal que marca a liberdade positiva. Demonstrada, pois, uma primeira característica do procedimento de aprovação da reforma que a evidencia como um sintoma de fragilização da democracia brasileira.

Passando, então, à questão da velocidade do procedimento, insta colher considerações feitas por Kingdon sobre o que ele denomina como "janelas de oportunidade". Pelo termo "janelas", o autor descreve as oportunidades para que os grupos de interesse ofertem seus pacotes de soluções para os problemas, alertando que tais grupos, dentro do processo permanente de "amaciamento" do sistema, mantém sempre prontas suas propostas para lidar com os aludidos problemas. Esses atores assim agem e se mantém justamente esperando o aparecimento da oportunidade - janela - propícia para emplacar as políticas públicas que Ihes interessam (KINGDON, 2007, p. 236-237).

Kingdon (2007, p. 236 - 237) assevera que a abertura dessas janelas pode ser previsível - por exemplo, eleições de novos políticos - ou imprevisível ilustrando com a situação de uma eleição tumultuada, que dá ensejo a uma rotatividade inesperada de decision - makers. Além do caráter (im) previsível das janelas, estas são ainda caracterizadas como pequenas e escassas, pois abrem-se poucas vezes e permanecem abertas por breve período, adjetivos que reforçam a importância de os atores interessados estarem em permanente alerta e prontidão na execução das formas de "amaciamento" do sistema.

A descrição encaixa-se com justeza ao panorama verificado no contexto da 
gestação e aprovação da reforma trabalhista, que assim pode ser descrito: a) elegeram-se basicamente dois problemas: crise econômica e elevado índice de desemprego; b) na seara política, deu-se, de forma imprevisível, uma alteração de governo através da deposição, por impeachment, da Presidente da República e, por conseguinte, um giro de 180 graus entre os partidos e parlamentares que compunham base aliada e oposição ao governo; c) considerando que, como pontuado anteriormente, a marca característica da relação capital $\mathrm{x}$ trabalho é a perene luta em busca de reformas que privilegiem um ou outro lado, o sistema político já vinha, desde sempre, sendo "amaciado" pelos grupos de interesse, como se pode notar pelas sucessivas reformas flexibilizantes na legislação social do trabalho ao longo do tempo, bem como pela ilustração de uma tentativa de extinção da Justiça do Trabalho em 1999; d) a janela política deu-se com o impeachment da Chefa do Poder Executivo em 31.8.2016, tendo o projeto de lei da reforma trabalhista sido apresentado em 23.12.2016; e) fez-se a ligação entre os problemas e as soluções apresentadas e amaciadas pelos grupos de interesse em velocidade espantosa, na apresentação da proposta na Câmara dos Deputados (menos de 4 meses após o impeachment), com aprovação, considerando o trâmite em ambas as Casas Legislativas, no prazo de aproximadamente 7 meses, e com períodos de recesso no meio da tramitação; f) a rapidez, tanto na proposição da medida quanto na sua aprovação, decorreu da necessidade de aproveitar uma rara, pequena e escassa janela política - impeachment - e de evitar que a dinâmica da existência dos problemas - crise econômica e desemprego - perdessem força e capacidade persuasiva.

Demonstra-se, assim, a velocidade incomum, para os parâmetros de uma democracia saudável - que, por definição, tem o contraditório democrático exaustivo como uma marca indelével -, com que a reforma trabalhista foi proposta e aprovada.

Somando-se este segundo fator com o anteriormente esposado, pode-se afirmar, então, que a reforma trabalhista revela-se como um sintoma de fragilização da liberdade positiva e de participação política, ameaçando os desígnios de uma autonomia ou um autogoverno democrático, objetivo, como visto, perseguido mesmo em uma democracia procedimental.

Em termos conclusivos, tem-se que a democracia procedimental, com as notas complementares da definição de democracia por orientação do processo, possui, embutidos na regra majoritária, os complexos vetores da liberdade, positiva 
e negativa, e da igualdade, de maneira articulada. A democracia procedimental, então, somente toma como legitimamente satisfeita a regra majoritária quando o procedimento de aprovação de uma lei - a reforma trabalhista, por exemplo - tiver ocorrido mediante a prévia garantia de participação efetiva dos votantes em tempo minimamente necessário para a formação de um entendimento esclarecido.

Considerando os vetores então lançados, constata-se que a reforma trabalhista revela um sintoma de fragilização da democracia brasileira, assim encarada em sua feição procedimental enriquecida com uma parte dos critérios de orientação para o processo, pelas seguintes razões: a) a aprovação em tempo exíguo e com velocidade espantosa de uma profunda reforma sobre matéria geralmente controvertida e geradora de desacordos, aproveitando-se de janela de oportunidade decorrente da ruptura provocada pelo impeachment, representa falta de materialização dos critérios de participação efetiva e de entendimento esclarecido; b) a culminância do procedimento em desrespeito aos ditos critérios, revela mácula da liberdade positiva em seu sentido material, resultando em aprovação de medida pelo princípio majoritário não antecedido dos fatores que legitimam a imposição da decisão da maioria sobre a totalidade dos participantes da comunidade política; c) dado o interesse econômico do capital em matéria alusiva a um dos principais custos de produção do sistema capitalista e tendo em linha de análise os próprios considerandos do relatório do projeto no Senado Federal, tem-se que a pressão dos grupos de interesse sobre as instâncias políticas ajudou na velocidade de aprovação da medida e, por conseguinte, contribuiu para um procedimento sem participação efetiva e entendimento esclarecido, desvelando a aprovação de projeto em desacordo com os postulados da democracia procedimental.

\section{CONSIDERAÇÕES FINAIS}

O Direito do Trabalho, enquanto mecanismo de garantia de direitos fundamentais, configura-se, em conjunto com a Carta Constitucional, como vetor normativo condicionante do agir estatal e do funcionamento da democracia brasileira, matizando de que modo o legislador infraconstitucional deve pautar sua atividade política no momento em que cogita patrocinar uma profunda reforma do conjunto normativo que edifica o Direito do Trabalho. 
A ligação entre Direito do Trabalho - e por conseguinte da reforma trabalhista - direitos fundamentais e democracia exigiu uma conceituação de democracia. Como visto neste ensaio, a definição desta envolve elementos descritivos e normativos que se correlacionam intrinsecamente, sendo adequado, então, afirmar a possibilidade de definições distintas de democracia, a depender dos diversos critérios compartilhados coletivamente que influem na sua concepção.

A concepção adotada para permitir a análise do problema de pesquisa foi a de democracia procedimental, acrescida de elementos da democracia orientada pelo processo, pois, como visto, este tipo de análise, ao propiciar o reconhecimento de possíveis falhas nos processos democráticos tradicionais, confere ao pesquisador a possibilidade de, em pesquisas futuras, identificando as causas das referidas falhas, propor possíveis alternativas que, aprimorando o modelo, podem resultar em um duplo ganho: a) o aperfeiçoamento do modelo que mais empodera o exercício da liberdade positiva pelos cidadãos, fortalecendo o ideal de autogoverno; b) a resolução de problemas inerentes à democracia pelos próprios protagonistas do modelo - o povo - de maneira global, geral, concertada, dialogada e sistematizada, em detrimento de resoluções a partir de sintomas, por instâncias que, apesar de conceitualmente democráticas, não estão ligadas diretamente aos referidos protagonistas e que atuam, no mais das vezes, impondo decisões verticalizadas e que não ofertam soluções sistematizadas, como sói ocorrer na atuação cada vez mais proeminente do Poder Judiciário.

Compreendidos os elementos que cercam a democracia procedimental, demonstrou-se que o ideal de autonomia e de autogoverno pretendido por ela pressupõe e exige não apenas a liberdade do tipo negativa, mas igualmente a liberdade positiva, com especial atenção para a necessidade de intensificação da participação política dos integrantes da sociedade. A materialização de uma plena participação política depende da verificação dos elementos "participação efetiva" e "entendimento esclarecido", como demonstrado.

De outro lado, verificou-se que a necessidade de fluxo de capital rumo à acumulação infinita deste - nota característica do sistema econômico capitalista sempre andou de mãos dadas com a exigência de respeito à liberdade negativa, solicitando um não agir interventivo do Estado na dinâmica do mercado como pressuposto central de um conceito de democracia. Percebeu-se que esta espécie de solicitação do capitalismo ganhou graus ainda mais elevados em tempos de 
neoliberalismo, reforçando a absoluta prevalência da liberdade negativa em oposição à liberdade positiva, como espécie de participação política capaz de colocar freios humanizantes à atividade capitalista.

Demonstrou-se que a dinâmica capitalista, para manter-se livre das amarras estatais, labora, conscientemente e inconscientemente, de forma a minar o alcance de um efetivo e proveitoso exercício da liberdade positiva e de participação política, expediente atestado e certificado tanto na constatação da atual apatia e passividade política da sociedade, quanto na verificação de ataques deliberados às estruturas formalmente concebidas para efetivar o exercício material de uma liberdade positiva representativa dos anseios do povo.

A partir da constatação da aludida forma de interação do capitalismo com os pilares da liberdade negativa e positiva, analisou-se e concluiu-se que a brusca alteração ocorrida no governo central, por meio do impeachment da Presidente Dilma Roussef, propiciou a entrada da reforma trabalhista na agenda do novo governo com a abertura de uma janela de oportunidade política para a célere aprovação da medida. No bojo desta, com velocidade espantosa, aprovou-se reforma legislativa que não fora validada democraticamente pela sociedade nas eleições.

Em termos conclusivos, tem-se, então o seguinte: a) em regra, a dinâmica capitalista tende a emprestar caráter absoluto à liberdade negativa, sempre propugnando a não intervenção estatal na esfera privada dos indivíduos e das empresas; b) a garantia absoluta da liberdade negativa exigida pelo sistema capitalista em tempos de neoliberalismo trabalha de modo a obscurecer e fragilizar as estruturas da democracia procedimental desenhadas para dar vazão e densificar o exercício da liberdade positiva; c) no caso brasileiro, apresentaram-se como problemas a crise econômica e o elevado desemprego e, à evidência de que o projeto político vencedor das eleições não contemplava a reforma trabalhista como medida apta a ofertar solução aos problemas, aproveitou-se a pequena janela de oportunidade derivada do impeachment para incluir tal projeto na agenda de governo e aprová-lo com extrema velocidade. Tais características do procedimento de aprovação da reforma trabalhista, aliado ao fato de que neste tema sempre ocorreram desacordos históricos e profundos, representam, então, a culminância de um processo que evidenciou um sintoma de fragilização da liberdade positiva e, por conseguinte, da Democracia Brasileira. 


\section{REFERÊNCIAS}

BARZOTTO, Luis Fernando. A Democracia na Constituição. São Leopoldo/RS: Unisinos, 2005.

CANOTILHO, José Joaquim Gomes. Constituição dirigente e vinculação do legislador: contributo para a compreensão das normas constitucionais programáticas. 2. ed. Coimbra: Coimbra Editora, 2001.

CONSTANT, Benjamin. Liberdade dos Antigos comparada à dos Modernos. Filosofia Política, n. 2. 1985.

CUNNINGHAM, Frank. Teorias da democracia: uma introdução crítica. Tradução Delmar José Volpato Dutra. Porto Alegre: Artmed, 2009.

Dilma desiste da reforma trabalhista após reações das centrais sindicais. G1. 5 fev. 2016. Disponível em http://g1.globo.com/jornal-nacional/noticia/2016/02/dilmadesiste-da-reforma-trabalhista-apos-reacoes-das-centrais-sindicais.html. Acesso em: 20 dez. 2017

DWORKIN, Ronald. Justiça para ouriços. Tradução: Marcelo Brandão Cipolla. São Paulo: Editora WMF Martins Fontes, 2014.

HARVEY, David. O enigma do capital: e as crises do capitalismo. Tradução de João Alexandre Peschanski. São Paulo, SP: Boitempo, 2011.

KINGDON, John W. Como chega a hora de uma ideia; Juntando as coisas. In: SARAVIA, Enrique; FERRAREZI, Elisabete (Org.). Políticas Públicas. Coletânea. Vol. 1 Brasília: ENAP, 2006.

MARMELSTEIN, George. Curso de direitos fundamentais. 3. ed. São Paulo: Atlas, 2011.

PMBD. Uma ponte para o futuro. Brasília. 29 out. 2015. Disponível em: http://pmdb.org.br/wp-content/uploads/2015/10/RELEASE-TEMER A4-28.10.15Online.pdf. Acesso em: $20 \mathrm{dez} .2017$

PT; ROUSSEFF, Dilma. Mais mudanças, mais futuro. 2014. Disponível em: http://divulgacand2014.tse.jus.br/divulga-cand2014/proposta/eleicao/2014/idEleicao/143/UE/BR/candidato/280000000083/idarquiv o/194? x=1404673131000280000000083. Acesso em: $20 \mathrm{dez} .2017$

ROSENFIELD, Denis L. A questão da democracia. São Paulo: Brasiliense, 1984.

SARTORI, Giovanni. Qué es la democracia? Madrid. Santillana Ediciones Generales, 2007

SENADO FEDERAL, Autor. Senado Federal - Notas Taquigráficas da sessão do Senado Federal para apreciação do texto da reforma trabalhista em 11.7.2017. Disponível em: https://www25.senado.leg.br/web/atividade/notas-taquigraficas/- 
/notas/s/23101. Acesso: $20 \mathrm{dez} .2017$.

STRECK, Lenio Luiz. Verdade e consenso: constituição, hermenêutica e teorias discursivas. 5. ed. rev., mod. e ampl. São Paulo: Saraiva, 2014.

TILLY, Charles. Democracia. Tradução de Raquel Weiss. Petrópolis/RJ: Vozes, 2013.

VERBICARO, Loiane Prado, FADEL, Ana Laura. Modelo de Democracia à luz da Teoria de Ronald Dworkin. In: Revista Unicuritiba, vol. 52, n, 3, 2018.

VERBICARO, Loiane Prado; GALUTTY, Pietra. Direito, controle judicial e democracia: 0 debate entre as teorias democráticas de Jeremy Waldron e Ronald Dworkin. Revista Direito em Debate, Ano XXVI, n. 47, 2017.

WALDRON, Jeremy. Derecho y desacuerdos. Marcial Pons, ediciones juridicas y sociales. Madrid, 2005. 